\title{
Setor pet na cidade de Solânea-PB: Análise mercadológica, tendências e perspectivas
}

\author{
Pet sector in the city of Solânea-PB: Market analysis, trends and perspectives \\ Sector pet en la ciudad de Solânea-PB: Análisis de mercado, tendencias y perspectivas
}

Recebido: 28/06/2021 | Revisado: 05/07/2021 | Aceito: 09/07/2021 | Publicado: 20/07/2021

\author{
Maria Isabel Mendonça da Silva \\ ORCID: https://orcid.org/0000-0002-4035-2858 \\ Universidade Federal da Paraíba, Brasil \\ E-mail: mariaisabelmds1@gmail.com \\ Emanuelle Alícia Santos de Vasconcelos \\ ORCID: https://orcid.org/0000-0002-8450-4542 \\ Universidade Federal da Paraíba, Brasil \\ E-mail: emanuellealicia@ hotmail.com \\ Péricles de Farias Borges \\ ORCID: https://orcid.org/0000-0003-3585-1342 \\ Universidade Federal da Paraíba, Brasil \\ E-mail: pericles@cca.ufpb.br \\ Lázaro de Souto Araújo \\ ORCID: https://orcid.org/0000-00016398-7533 \\ Universidade Federal da Paraíba, Brasil \\ E-mail: lazaro.souto@hotmail.com
}

\begin{abstract}
Resumo
Com o passar dos anos, os animais de estimação começaram a ser vistos como membros das famílias. Muitos tutores querem proporcionar tudo o que estiver ao alcance para que todas as necessidades de seus animais, muitas vezes chamados de "filhos", sejam supridas, o que pode ser evidenciado pela manutenção nos níveis de demanda no setor, mesmo em tempos de crise. Assim, esta pesquisa teve como objetivo estudar o comportamento do mercado PET da cidade de Solânea-PB, avaliando a oferta e a demanda presente na região. Tendo como aporte teórico e bibliográfico, as definições e teorias do estudo e planejamento estratégico de mercado, procedeu-se com a aplicação de questionários destinados ao mercado consumidor, sendo tutores de pelo menos um animal de estimação, e aos ofertantes da cidade. Após análise dos dados, mediante abordagem qualiquantitativa, como principais resultados, verifica-se a carência de variedade na oferta de produtos/serviços como principal deficiência dos ofertantes relatada pelos consumidores, além da demanda por serviços como diagnóstico por imagem, atendimento por especialidades e hotel para cães e gatos, demonstrando potencialidades de negócio na cidade. Sob a ótica dos ofertantes, o estudo apontou para algumas dificuldades no relacionamento com os clientes, sobretudo no quesito valorização dos serviços e do profissional da Medicina Veterinária.
\end{abstract}

Palavras-chave: Mercado pet; Medicina veterinária; Pesquisa de mercado.

\begin{abstract}
Over the years, pets began to be seen as members of families. Many tutors want to provide everything they can to ensure that all the needs of their animals, often called "children," are met, which can be evidenced by maintaining demand levels in the industry, even in times of crisis. Thus, this research aimed to study the behavior of the PET market in the city of Solânea-PB, evaluating the supply and demand present in the region. Having as theoretical and bibliographic support, the definitions and theories of the study and strategic market planning, proceeded with the application of questionnaires intended for the consumer market, being tutors of at least one pet, and the offerers of the city. After analyzing the data, using a qualitative and quantitative approach, as the main results, there is a lack of variety in the offer of products / services as the main deficiency of providers reported by consumers, in addition to the demand for services such as diagnostic imaging, specialty care and hotel for dogs and cats, demonstrating business potential in the city. From the perspective of providers, the study pointed to some difficulties in the relationship with clients, especially regarding the valuation of services and the professional of Veterinary Medicine.
\end{abstract}

Keywords: Pet market; Veterinary medicine; Market research.

\section{Resumen}

Con el paso de los años, las mascotas comenzaron a verse como miembros de una familia. Muchos tutores quieren poner todo a su alcance para que se cubran todas las necesidades de sus animales, a menudo llamados "niños", lo que se evidencia en el mantenimiento de los niveles de demanda en el sector, incluso en tiempos de crisis. Así, esta investigación tuvo como objetivo estudiar el comportamiento del mercado de PET en la ciudad de Solânea-PB, evaluando la oferta y demanda presente en la región. Teniendo como soporte teórico y bibliográfico, las definiciones y 
teorías del estudio y planificación estratégica del mercado, se procedió a la aplicación de cuestionarios destinados al mercado consumidor, siendo tutores de al menos una mascota, y a los concursantes de la ciudad. Luego de analizar los datos, utilizando un enfoque cualitativo, como principales resultados, existe una falta de variedad en la oferta de productos / servicios como la principal deficiencia de los proveedores reportada por los consumidores, además de la demanda de servicios como el diagnóstico por imagen servicio por especialidades y hotel para perros y gatos, demostrando potencial comercial en la ciudad. Desde la perspectiva de los proveedores, el estudio apuntó algunas dificultades en la relación con los clientes, especialmente en términos de valoración de servicios y profesionales en Medicina Veterinaria.

Palabras clave: Mercado de mascotas; Medicina veterinaria; Investigación de mercado.

\section{Introdução}

Segundo a Associação Brasileira da Indústria de Produtos para Animais de Estimação (ABINPET, 2018), a população de animais de estimação no Brasil já supera 130 milhões, representando o terceiro maior mercado PET do mundo em faturamento. Em 2017, o setor faturou 20,3 bilhões de reais, tendo um crescimento de 4,95\% em 2016/2017, e esse crescimento continuado é resultado da mudança de status que os animais de estimação vêm ganhando com o passar do tempo nas famílias brasileiras.

Não é novidade que os animais de estimação têm um lugar especial nos lares de muitos brasileiros. Com o passar dos anos, começaram a ser vistos não só como bichinhos de estimação, mas como membros das famílias. Os tutores querem proporcionar tudo o que estiver ao alcance para que todas as necessidades de seus "amigos de 4 patas" sejam supridas, o que pode ser evidenciado pela manutenção nos níveis de demanda, mesmo em tempos de crise.

Um dos motivadores do crescimento do número de animais de estimação é o proporcional aumento da população humana, o que gera, consequentemente, um aumento no número de animais de estimação nos lares. Além disso, o crescimento do mercado pet está relacionado à humanização desses animais de estimação, pois à medida que o contato com as famílias vai crescendo, acaba gerando o aumento do vínculo afetivo entre eles. Diante de tal cenário, os tutores visam dispensar uma parte de seus rendimentos na demanda por serviços de saúde, alimentação, beleza e bem-estar animal. Outro fator explicativo está relacionado às estruturas familiares, onde em muitos casos, pessoas que vivem sozinhas optam pela companhia de um animal de estimação. Além disso, também se pode atribuir esse recente cenário ao crescimento do poder aquisitivo das famílias brasileiras, que os permite adquirir e manter os cuidados com um animal de estimação. (Muller, 2012)

De acordo com o Instituto Brasileiro de Geografia e Estatística (IBGE, 2017), a população de Solânea-PB no último censo realizado em 2010 era de 26.693 pessoas, e a população estimada para 2019 foi de 26.407 pessoas. A classe C, também conhecida na última década como "nova classe média", voltou a ter um crescimento de 2017 para 2018, subindo no ranking de $50 \%$ para 51\%, que em números representa um acréscimo de 2 milhões de pessoas novas na classe. Estima-se que 106 milhões de brasileiros façam parte da classe $\mathrm{C}$, e com o aumento da renda, a projeção para 2019 é que a classe tenha posse de $\mathrm{R} \$ 1,57$ trilhão. (Scaramuzzo; Scheller, 2019)

Segundo pesquisa realizada pelo Serviço de Proteção ao Crédito (SPC Brasil) e pela Confederação Nacional de Dirigentes Lojistas (CNDL) (2017), essa direção a um tratamento cada vez mais humanizado, possibilita inúmeras oportunidades de negócio no setor, como por exemplo planos de saúde, centros de tratamento médico, espaços para socialização e realização de eventos entre donos e seus pets, hotéis e creches, brinquedos e linhas de alimentos específicos para cada fase ou necessidade do pet naquele momento de sua vida.

Para Antônio e Dutra (2008), o marketing é a “alma do negócio", e sem a sua utilização nenhuma empresa consegue ter progresso. Para que esse progresso possa acontecer de forma eficaz, é fundamental conhecer os fatores externos, fazendo uso da pesquisa de mercado. Compreender as particularidades que envolvem os animais de estimação, os seus tutores, as características do ambiente em que vivem e as necessidades que possuem relacionadas ao consumo de produtos e serviços do mercado pet é de grande importância para se estabelecer estratégias para que as suas necessidades possam ser supridas em termos de oferta e demanda de mercado. Identificando o que o consumidor deseja, o empreendedor veterinário pode se inserir no mercado sabendo 
das expectativas de seus consumidores e dessa forma obter êxito num mercado que está se tornando cada vez mais competitivo (Elizeire, 2013). Além disso, é interessante que os tutores conheçam os principais serviços e produtos que podem oferecer ao seu pet, sendo destacado aqui o grande papel do marketing veterinário no setor.

A contínua transformação no setor econômico e a facilidade de acesso à informação tornam os consumidores cada vez mais exigentes no momento de escolher um produto ou serviço que irão adquirir, e por isso, a competição no mercado tem crescido cada vez mais para atender as necessidades dos consumidores (Graf, 2016). Têm-se como problema a respeito do tema os poucos estudos realizados para entender o comportamento do mercado e as demandas que muitas vezes os consumidores têm, mas não são conhecidas. Principalmente em cidades pequenas, onde muitas vezes não são realizados estudos de mercado para conhecimento da possível (ou não) demanda. Levando em consideração os pontos citados, o problema de pesquisa que se formula é: "como se comporta o mercado pet na atualidade, em termos de oferta e demanda, na cidade de Solânea-PB? "

O mercado pet cresce constantemente no Brasil e resiste às crises, e esse fato está muito relacionado à consideração que os tutores têm por seus animais de estimação. Conhecer o mercado em que se está inserido ou vai se inserir é de extrema importância para que um negócio seja próspero e atinja os objetivos esperados, por isso, dentro da área da medicina veterinária, a realização deste trabalho teve como objetivos estudar o comportamento do mercado pet na cidade de Solânea-PB, para conhecer o comportamento dos consumidores em potencial, os tutores de pets, a fim de verificar se o mercado está atendendo a demanda e quais são as expectativas desses consumidores e identificar o perfil socioeconômico dos tutores de pets. Além disso, esse estudo visa contribuir para a atuação do médico veterinário como empreendedor e gestor, perpassando as habilidades técnicas aprendidas no ambiente acadêmico. E por fim, suprir a carência de informações para o mercado local, devido à ausência de dados e pesquisas.

\section{Metodologia}

Este estudo buscou aprofundar o conhecimento a respeito do mercado pet no município de Solânea-PB, utilizando os seguintes processos metodológicos: revisão bibliográfica, coleta de dados e análise dos dados.

\subsection{Tipo de pesquisa/revisão bibliográfica}

Quanto aos objetivos, o presente trabalho pode ser classificado como pesquisa de caráter exploratório, ou seja, é um tipo de pesquisa onde o objetivo maior é permitir maior contato com o problema, a fim de torná-lo mais explícito e construir hipóteses. Com relação aos procedimentos, o presente trabalho pode ser caracterizado como pesquisa bibliográfica. A pesquisa bibliográfica é realizada a partir da verificação de referências teóricas já verificadas, e publicadas por meios tanto escritos quanto eletrônicos, como livros, artigos científicos ou sites. (Gerhardt; Silveira, 2009)

Para a realização da revisão bibliográfica foram utilizados livros, artigos científicos, monografias, dissertações, guias do Conselho Federal de Medicina Veterinária (CFMV) e dados da Associação Brasileira da Indústria de Produtos para Animais de Estimação (ABINPET).

\subsection{Fonte e coleta de dados}

O projeto foi submetido ao Comitê de Ética em Pesquisa do Centro de Ciências da Saúde - CEP/CCS da Universidade Federal da Paraíba através da Plataforma Brasil, e após aprovação foi iniciada a coleta de dados. Foram coletados dados do mercado consumidor e dos ofertantes de produtos e serviços do município de Solânea-PB. Como instrumento para coleta de dados foi feito uso de questionários, que tem como uma das vantagens viabilizar respostas anônimas e não influenciadas pela opinião do entrevistador (Pereira, et al., 2018). Questionários do tipo semiaberto, com questões diretas e indiretas, predominantemente sendo questões de múltipla escolha, foram aplicados tanto presencialmente quanto através do gerador de formulários do Google Docs. Foram aplicados questionários em 3 estabelecimentos e 50 consumidores, no período de setembro 
a outubro de 2019. Foi critério de participação da pesquisa do mercado consumidor: participantes com idade igual ou superior a 18 anos, que tenham a tutoria de pelo menos 1 animal de estimação.

\subsection{Análise dos dados/abordagem qualiquantitativa}

Para o tratamento dos dados foi utilizada uma abordagem qualiquantitativa. A pesquisa quantitativa usa metodologias estruturadas e instrumentos formais para coletar os dados e analisar esses dados numéricos utilizando processos estatísticos. Já a pesquisa qualitativa tem como foco o subjetivo como forma de compreender e interpretar as experiências e analisa os dados com um método organizado, porém intuitivo. As características positivas de um complementam as negativas do outro, sendo essenciais ao maior desenvolvimento da ciência. (Gerhardt; Silveira, 2009)

\subsection{População e amostra}

Devido à escassez de registros a respeito da quantidade de pessoas tutoras de animais de estimação para a região avaliada, há dificuldade, do ponto de vista estatístico, da determinação do tamanho exato da população. Com isso, aplicou-se o sistema de amostragem não probabilística por acessibilidade, que segundo Mattar (1996), é aquela na qual a escolha dos elementos da população que irão integrar a amostra depende ao menos em parte do julgamento do pesquisador ou entrevistador de campo. A escolha da amostragem não probabilística se justifica quando:

a) os conhecimentos estatísticos conhecidos pelo pesquisador não são suficientes; (Aaker, Kumar \& Day ,1995)

b) quando se faz necessária a facilidade operacional; (Aaker, Kumar \& Day ,1995)

c) limitações de tempo, recursos financeiros, materiais ou "pessoas". (Mattar, 1996)

\section{Resultados e Discussão}

\subsection{Análise dos serviços veterinários ofertados}

Foram avaliados três estabelecimentos, onde o estabelecimento A e B possuíam um veterinário, e o estabelecimento C possuía dois veterinários. Os serviços ofertados por ambos os estabelecimentos estão listados na Tabela 1.

Tabela 1. Serviços veterinários ofertados em Solânea-PB.

\begin{tabular}{l|lll}
\hline Serviços ofertados & Estabelecimento A & Estabelecimento B & Estabelecimento C \\
\hline Consultas & $\mathrm{X}$ & $\mathrm{X}$ & $\mathrm{X}$ \\
Vacinação & $\mathrm{X}$ & $\mathrm{X}$ \\
Exames laboratoriais: & & $\mathrm{X}$ \\
$\quad$ Hemograma & $\mathrm{X}$ & $\mathrm{X}$ \\
$\quad$ Bioquímicos & $\mathrm{X}$ & $\mathrm{X}$ \\
$\quad$ Urinálise & & \\
$\quad$ Parasitológico & & $\mathrm{X}$ \\
Radiologia & & $\mathrm{X}$ \\
Ultrassonografia & $\mathrm{X}$ & \\
Cirurgias & & - & \\
Internamento & & & Testes rápidos \\
Banho e tosa & - & & \\
Outros & & & \\
\hline
\end{tabular}

Fonte: Autores (2019). 
De acordo com os dados avaliados na Tabela 1, nota-se que o estabelecimento $\mathrm{C}$ é o que apresenta maior variedade de serviços, seguido do estabelecimento A. O estabelecimento B realiza apenas vacinação. A pouca variedade de serviços ofertados apresentados na Tabela 1, pode ser justificada pela baixa rotatividade de clientes por ser uma cidade de pequeno porte.

Quando indagados a respeito dos atendimentos por mês, o veterinário do estabelecimento A afirmou realizar em média 44 atendimentos, sendo 2 por dia. No estabelecimento B não são realizados atendimentos, e no estabelecimento $\mathrm{C}$ a média de atendimentos de um dos veterinários é de 66 atendimentos e do outro é de 44 atendimentos, totalizando 100 atendimentos mensais. $\mathrm{O}$ maior quantitativo justifica-se pelo fato do estabelecimento $\mathrm{C}$ apresentar maior variedade de produtos e serviços prestados.

Os produtos e serviços mais procurados, segundo os ofertantes do setor, estão apresentados no Gráfico 1.

Gráfico 1. Produtos e serviços mais procurados, segundo os ofertantes do setor.

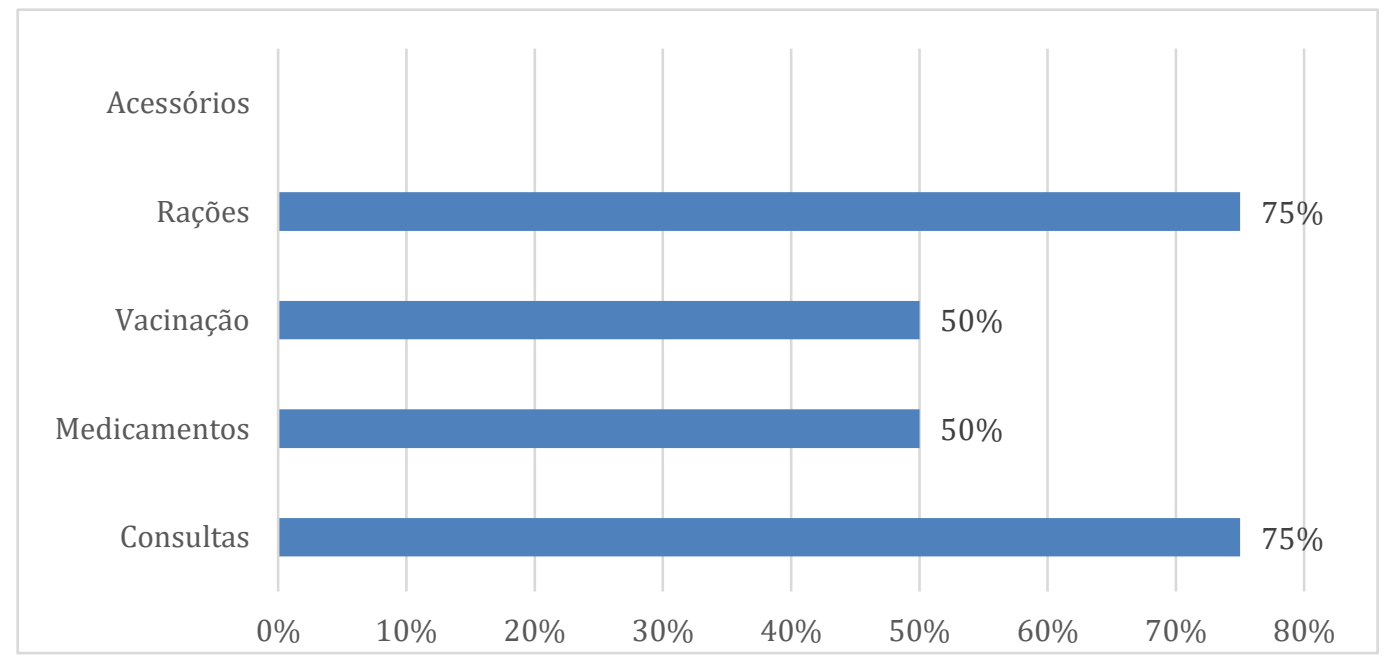

Fonte: Autores (2019).

A respeito da maioria dos serviços e produtos demandados (Gráfico 1), o estabelecimento A e C citaram consultas, medicamentos, vacinação e rações. Já o estabelecimento B citou apenas medicamentos e rações. Nenhum dos estabelecimentos citou acessórios (brinquedos, camas, etc.) como principais produtos procurados. Tais dados, segundo a percepção dos ofertantes locais, sugerem que, em grande medida, uma das maiores preocupações dos tutores concentra-se nos cuidados com a saúde animal, refletindo uma mudança de postura dos tutores, que estão cada vez mais conscientes acerca de uma criação responsável de seus animais. De acordo com pesquisa realizada pelo SPC Brasil e pela CNDL (2017), para os tutores entrevistados os cuidados com a saúde foram citados por 78,8\% dos entrevistados como item mais importante a ser proporcionado.

Os dados referentes a percepção dos médicos veterinários em relação aos tutores estão apresentados no Gráfico 2. 
Gráfico 2. Percepção dos médicos veterinários em relação aos tutores.

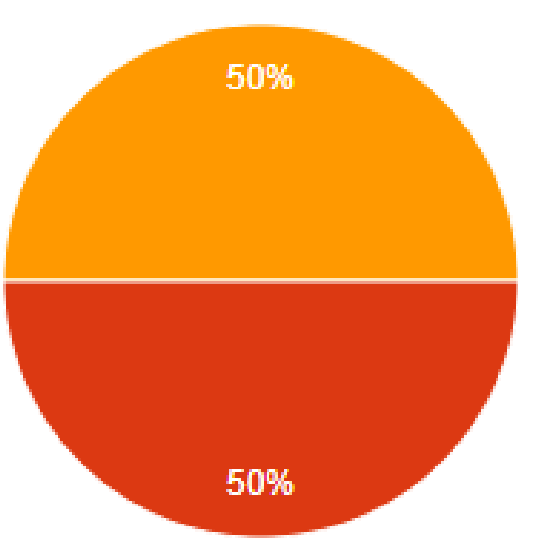

Valorizam o médico veterinário e acham o preço cobrado justo

- A maioria não tem condições de pagar pelos serviços

Não querem pagar o valor cobrado

Fonte: Autores (2019).

Foi exposta aos veterinários a questão a respeito do comportamento dos tutores e a valorização do profissional (Gráfico 2), onde 50\% dos Veterinários entrevistados afirmaram que a maioria dos tutores não tem condições de pagar pelos serviços e os outros 50\% afirmaram que os tutores não querem pagar o valor cobrado. Nenhum dos quatro veterinários entrevistados acham que os tutores valorizam o médico veterinário e acham o preço cobrado justo. Uma das dificuldades da valorização do médico veterinário pode ser resultado de anos de "má educação" dos próprios profissionais e também dos clientes, pois muitas vezes o comum é discutir sobre o preço e muitas vezes o valor é deixado fora da conversa. Mercader (2013) relata que o discutir com os clientes sobre os preços dos serviços e muito pouco sobre o valor é um dos dez erros mais comuns dos veterinários, sendo a conscientização a respeito da mudança dessa visão, um dos passos para um melhor reconhecimento do trabalho do profissional.

Por fim, os Veterinários foram indagados com a seguinte questão: "Para você, qual a maior dificuldade do mercado pet atualmente?". As respostas estão listadas abaixo:

- A concorrência desleal e falta de ética dos colegas médicos veterinários

- A atual situação socioeconômica que vive a nossa república

- Falta de fiscalização do CRMV em relação aos "práticos"

- Falta de profissionalismo dos colegas veterinários

- Ausência de práticas públicas que fomentem a profissionalização, tecnificação e investimento

- Poder socioeconômico e educativo dos clientes

- A falta de conscientização de tutores em relação a pagar consulta

- Lidar com prescrição de vendedores de farmácias

- Uso indiscriminado de medicamentos, sem consultar o animal.

Tais fatores, de um modo geral, podem representar para os profissionais desse mercado, assim como para os futuros empreendedores, como possíveis debilidades e ameaças para o pleno desenvolvimento do Setor PET no município de SolâneaPB, ensejando assim estratégias de planejamento mercadológico e estratégico para minimizá-las.

\subsection{Análise do perfil dos consumidores do mercado pet}

Foram aplicados 50 (cinquenta) questionários com o auxílio do Google formulários e presencialmente, com os consumidores do mercado PET da cidade de Solânea-PB que possuíam pelo menos um animal de estimação.

A faixa etária dos entrevistados está apresentada no Gráfico 3. 
Gráfico 3. Faixa etária dos entrevistados.

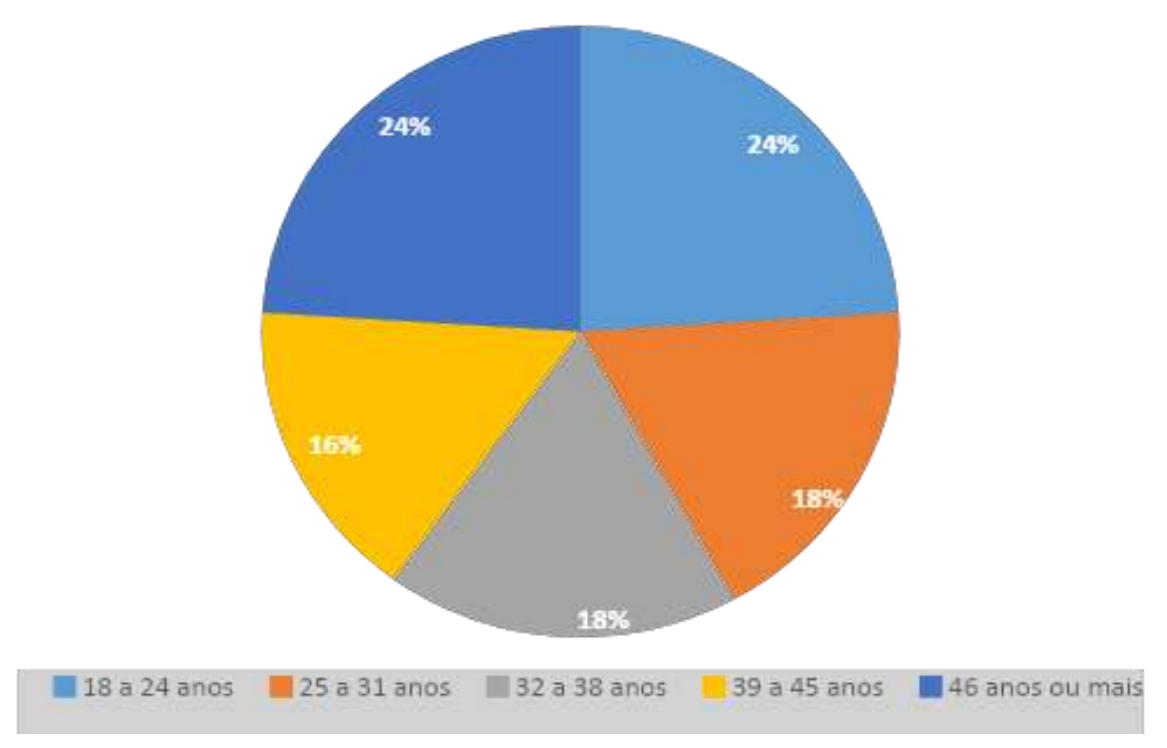

Fonte: Autores (2019).

Dos cinquenta entrevistados, $78 \%$ foram mulheres e $22 \%$ foram homens. Como se pode observar no Gráfico 3, $24 \%$ dos entrevistados apresenta faixa etária entre 18 a 24 anos, $18 \%$ entre 25 a 31 anos, $18 \%$ entre 32 a 38 anos, $16 \%$ entre 39 a 45 anos, e os outros $24 \%$ apresentavam idade igual ou superior a 46 anos. Assim, de acordo com a amostra analisada, compreendese que a maior concentração de tutores se dá entre as mulheres, tendo mais incidência no grupo das mais jovens e das mais velhas (após 46 anos de idade), apontando para um mercado relativamente diversificado em termos etários. Em relação a esses dados, Muller (2012) destaca que é importante que os ofertantes do mercado PET saibam diferenciar seus consumidores e pensar em estratégias diferenciadas para conquista dos clientes de acordo com cada faixa etária e suas necessidades.

Em relação à grande incidência de mulheres tutoras de pets, entende-se que possa haver ligação com o fato de que as mesmas são mais cuidadosas e atentas no momento de cuidar de um animal, muitas vezes tratando seus pets como filhos. Em estudo realizado por Stoeckel et al. (2014), mulheres que possuíam crianças e filhos foram submetidas a exames de ressonância magnética enquanto viam fotos de crianças e cães, incluindo a de seus próprios filhos e cães. Os pesquisadores observaram que havia semelhanças na forma com que diversas partes do cérebro das mães reagiram à imagem dos seus filhos e cães. Ao visualizarem a foto de seu filho, foi notada atividade cerebral no mesencéfalo (área tegmental ventral e substância negra), envolvida em recompensa/formação de vínculo. Por outro lado, a ativação do giro fusiforme que é responsável pelo processamento visual dos rostos e cognição social foi maior quando as mães viam fotos de seus cães.

A respeito do estado civil, $44 \%$ dos entrevistados declararam estar solteiros, $44 \%$ casados/união estável, $8 \%$ divorciados, $2 \%$ viúvos e $2 \%$ namorando. Dos entrevistados 30\% afirmaram morar com 2 pessoas, $22 \%$ com 4 pessoas, $18 \%$ com 3 pessoas, 14\% com 1 pessoa, $10 \%$ com 5 pessoas ou mais e apenas $6 \%$ afirmou morar sozinho. Com relação à formação do núcleo familiar, a amostra utilizada contradiz o senso comum que muitas vezes associa a criação de animais a pessoas sozinhas, que aqui representou apenas $6 \%$ da amostra.

Dos 50 (cinquenta) entrevistados, $88 \%$ afirmaram morar em casas e $22 \%$ em apartamentos. Um fator associado a esse resultado é o fato de que em cidades pequenas o padrão predominante é a moradia em casas, além disso, morar em casas possibilita aos tutores proporcionar maior liberdade aos animais, e também facilita a criação de animais de grande porte em questão de espaço.

A renda mensal dos entrevistados está apresentada no Gráfico 4. 
Gráfico 4. Renda mensal dos entrevistados considerando todos os membros da família.

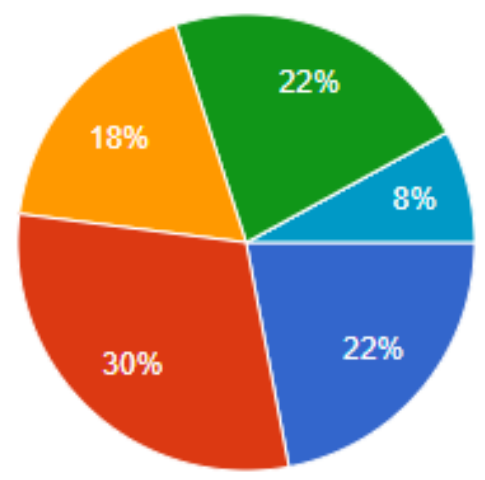

Até 1 salário mínimo (até RS 954,00)

De 1 a 2 salários mínimos (de RS 954,01 a RS 1908,00)

De 2 a 3 salários mínimos (de RS 1908,01 a 2862,00 )

De 3 a 5 salários mínimos (de RS 2862,01 a RS 4770,00 )

De 5 a 7 salários mínimos (de RS 4770,01 a RS 6678,00 )

Mais de 7 salários mínimos (mais d..

Fonte: Autores (2019).

No que diz respeito à renda mensal, considerando todos os membros da família, podemos observar, no Gráfico 4, que $30 \%$ dos entrevistados afirmaram receber de 1 a 2 salários mínimos, 22\% afirmou receber até 1 salário, $22 \%$ recebe de 3 a 5 salários, $18 \%$ recebe de 3 a 6 salários e $8 \%$ recebe mais de 7 salários mínimos. Tais dados revelam que a maioria dos entrevistados se concentra nas classes socioeconômicas mais baixas (classes D e E), o que pode ser um reflexo das próprias características de rendimentos do município no qual a pesquisa se ambientou, uma vez que, segundo o IBGE (2017), o salário médio mensal dos solanenses é de 1,8 salários mínimos.

Em matéria publicada pela Você S/A, Poli (2017), indaga os leitores a respeito do que faz o mercado PET se destacar num período de crise em que as pessoas estão cortando gastos, e responde da seguinte maneira: a crescente transformação do comportamento dos donos de Pets, pois nos últimos anos, os animais deixaram de ser apenas "animais de estimação" e passaram a ser considerados membros da família. Assim, podemos notar analisando os dados coletados nesta pesquisa, que independente da renda mensal das famílias, que aqui em sua maioria foi de 1 a 2 salários mínimos, os tutores comprometem algum valor mensal para o cuidado com seus animais.

O nível de escolaridade dos entrevistados está apresentado no Gráfico 5. 
Gráfico 5. Nível de escolaridade dos entrevistados.

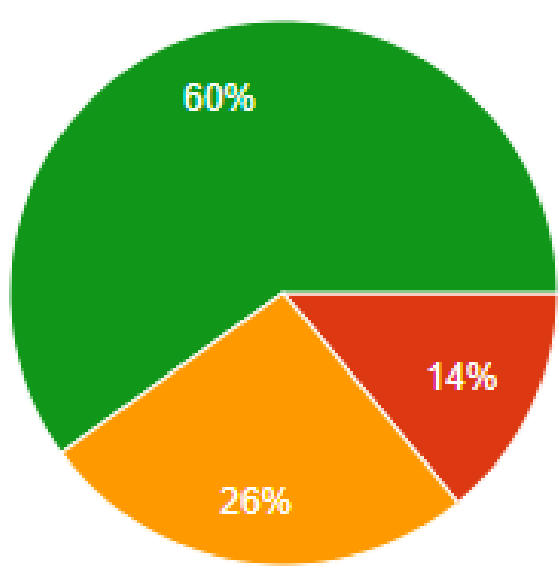

\section{Sem escolaridade}

Ensino fundamental completo

Ensino médio completo

Ensino Superior completo ou cursando

Fonte: Autores (2019).

Sobre o nível de escolaridade, $60 \%$ dos entrevistados afirmou possuir ensino superior completo ou cursando, $26 \%$ ensino médio completo e $14 \%$ ensino fundamental completo, nenhum dos entrevistados afirmou não possuir escolaridade. (Gráfico 5). O nível de escolaridade pode impactar no setor PET, uma vez que indivíduos mais escolarizados, são, naturalmente, mais informados a respeito de questões de saúde e bem-estar animal, demandando mais produtos e serviços do segmento.

A quantidade de animais por tutor entrevistado está apresentada no Gráfico 6.

Gráfico 6. Quantidade de animais por tutor entrevistado.

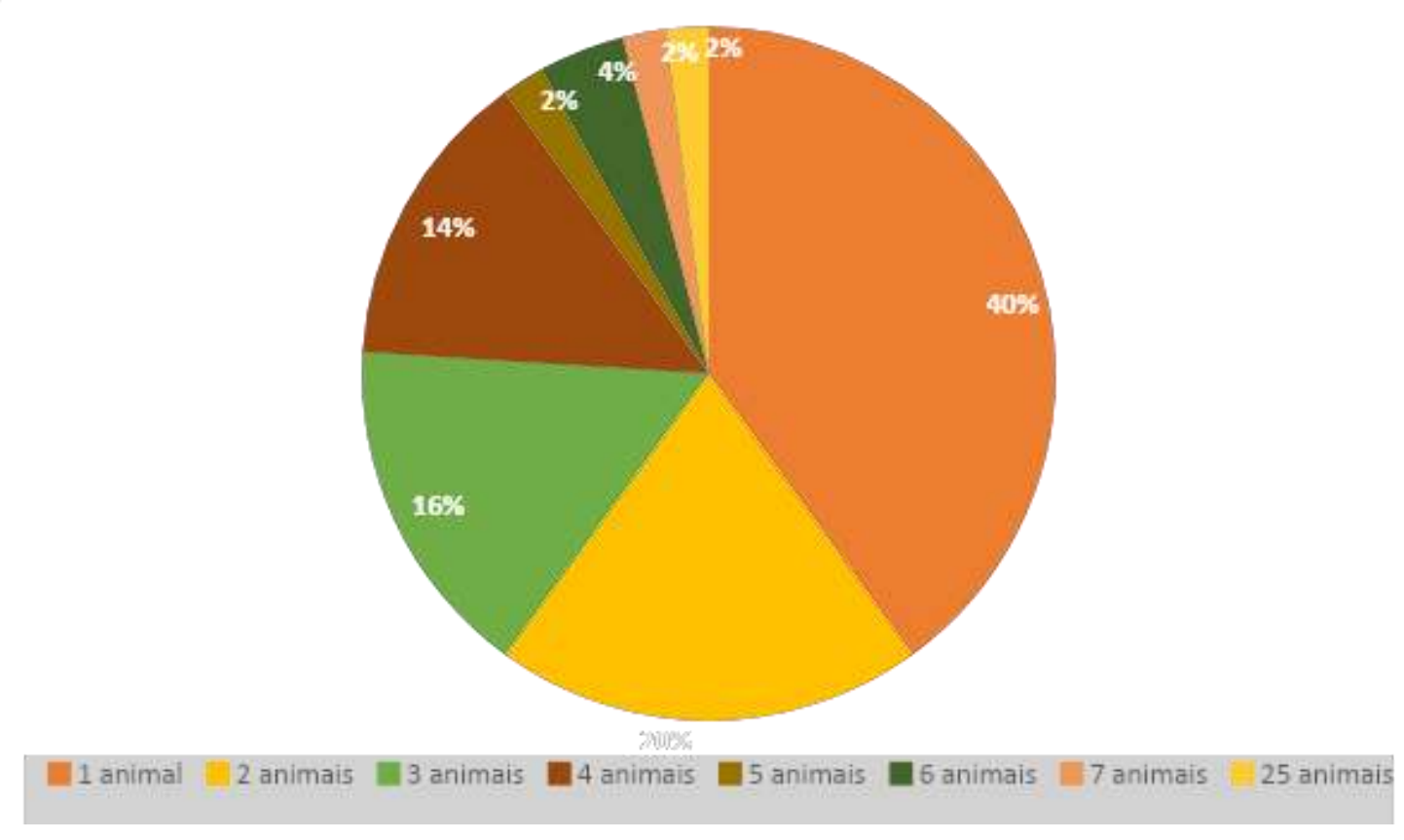

Fonte: Autores (2019). 
No que diz respeito à quantidade de animais que as famílias possuem, a maioria dos entrevistados (Gráfico 6) relatou ter apenas 1 animal de estimação no seu núcleo familiar, representando $40 \%$ dos entrevistados, $20 \%$ dos entrevistados relataram possuir 2 animais de estimação, 16\% relataram possuir 3 animais de estimação, 14\% possuem 4 animais, $4 \%$ relatou possuir 6 animais, $2 \%$ representam a tutoria de 5 animais, $2 \%$ de 7 animais e outros $2 \%$ de 25 animais em seus lares.

Os tipos de animais presentes nos lares dos entrevistados estão apresentados no Gráfico 7.

Gráfico 7. Animais presentes nos lares dos entrevistados.

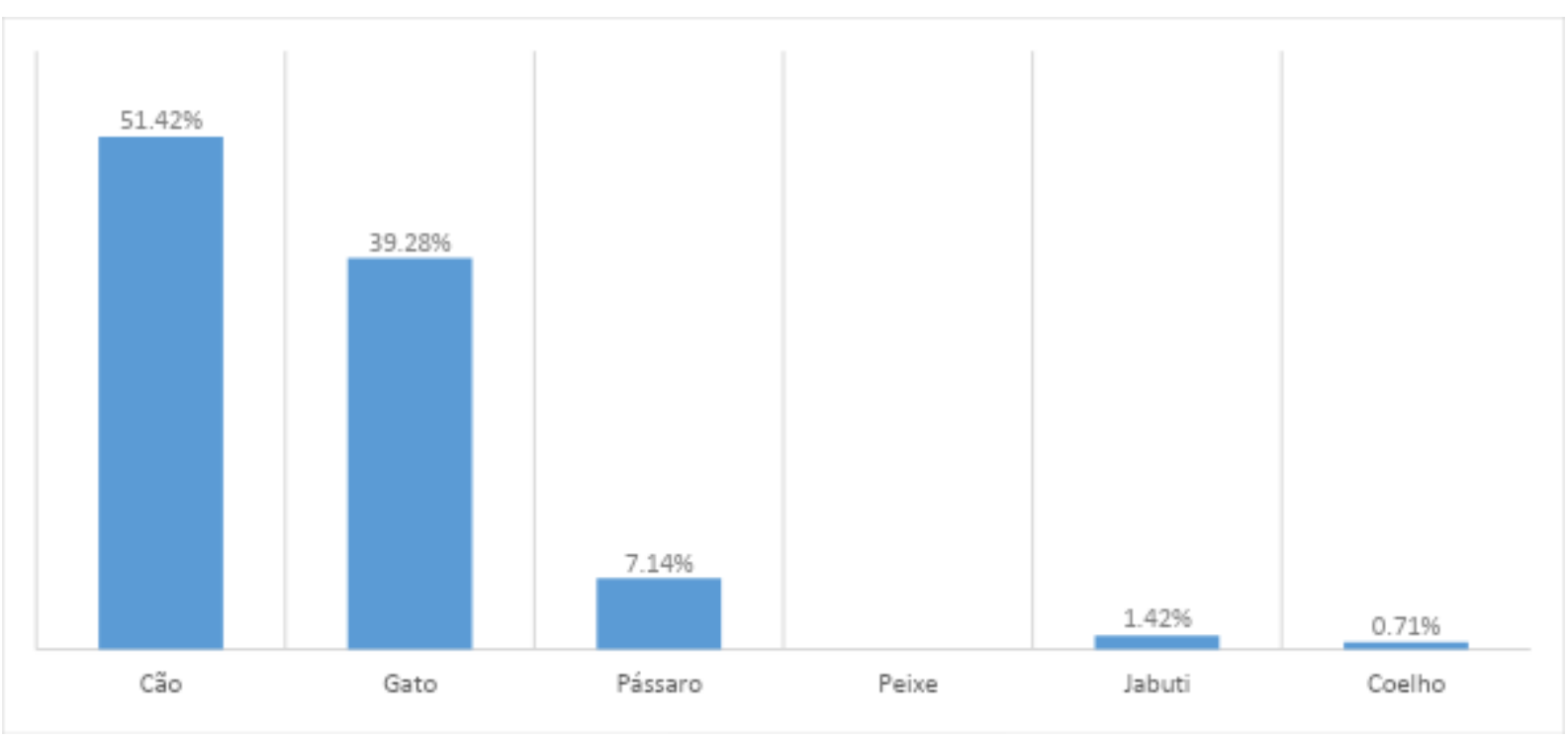

Fonte: Autores (2019).

O total de animais citados na pesquisa equivaleu a 140 animais, dos quais, de acordo com o Gráfico 7, os cães são os predominantes, equivalendo a 51,42\% dos animais, seguido dos gatos que representam 39,28\% dos animais citados, 7,14\% citaram pássaros, e em menor quantidade foram citados Jabutis e coelho, representando 1,4\% e 0,71\%, respectivamente. Em pesquisa realizada por Alcoforado (2018), para o Litoral Norte da Paraíba, foram encontradas proporções semelhantes, onde do total de animais contabilizados, 51,14\% dos animais eram cães, 35,61\% eram gatos, 8,67\% eram pássaros, 3,19\% eram jabutis, e um hamster, um peixe e um coelho representando $0,45 \%$ cada um. Seguindo a mesma proporção, um estudo realizado pelo SPC Brasil e pela CNDL (2017), constatou que dos tutores de animais, 78,8\% possuíam cães, $42,1 \%$ possuíam gatos e 17,5\% pássaros. Percebe-se que a escolha por outros tipos de animais de companhia vem crescendo, entretanto em sua maioria as pessoas ainda escolhem como companheiros os cães, e não é à toa que estes levam o título de "melhores amigos do homem".

Em pesquisa realizada por Santos et al. (2021), 39,2\% dos animais presentes nos lares eram cães. De acordo com a Pesquisa Nacional de Saúde 2013, realizada pelo IBGE (2015), que estimou a proporção de domicílios com cães e gatos, 44,3\% das casas do País possuíam pelo menos um cão. A população de cães em lares brasileiros foi estimada em 52,2 milhões, apontando uma média de 1,8 cão por lar. Relatou também que 17,7\% dos lares do país possuíam pelo menos um gato, onde a população de gatos em domicílios foi em média 22,1 milhões, representando aproximadamente 1,9 gato por lar. Dados que coincidem com a presente pesquisa, onde houve prevalência de cães nos lares, e em segundo lugar a presença de gatos.

As raças de cães presentes nos lares dos entrevistados estão apresentadas no Gráfico 8. 
Gráfico 8. Raças de cães presentes nos lares dos entrevistados

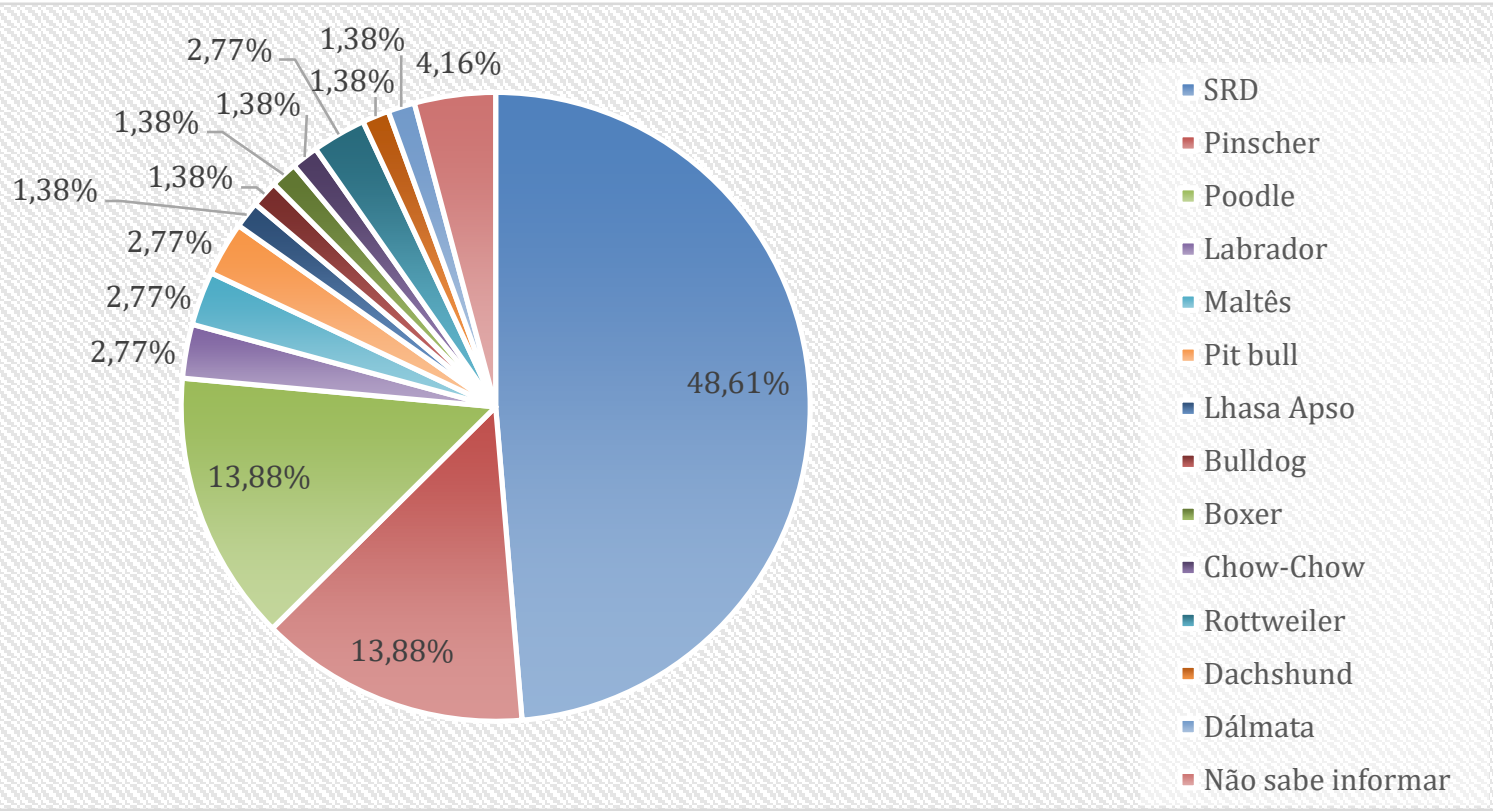

Fonte: Autores (2019).

Os animais mais citados foram os cães, sendo o total de 72 cães citados, dos quais em relação às raças de acordo com o gráfico 8, estima-se que 48,61\% são sem raça definida, 13,88\% são da raça Pinscher, e 13,88\% são da raça Poodle, representando as três principais raças citadas. Foram citadas as raças Labrador, Maltês, Pitbull, Rottweiler, representando cada uma 2,77\% do total de raças citadas. As raças Lhasa apso, Bulldog, Boxer, Chow-chow, Dachshund e Dálmata representam cada uma 1,38\% das raças citadas. Dos entrevistados, 4,16\% não souberam informar a raça de seus animais.

As raças de gatos presentes nos lares dos entrevistados estão apresentadas no Gráfico 9.

Gráfico 9. Raças de gatos presentes nos lares dos entrevistados.

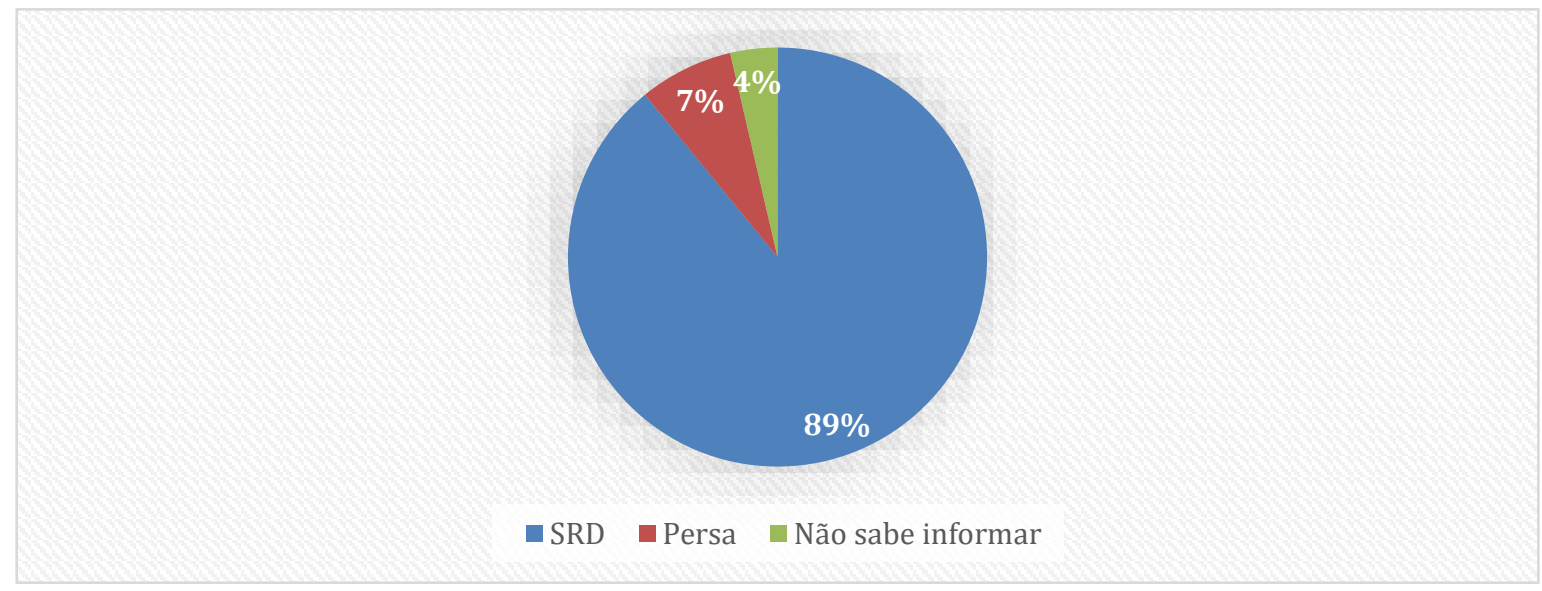

Fonte: Autores (2019).

Dos 140 animais citados, 55 foram gatos, ocupando o segundo lugar no número de animais citados. Em relação às raças mais citadas dos gatos, podemos notar, de acordo com o Gráfico 9, a prevalência é de animais sem raça definida representando 
89\% dos animais citados, em seguida $7 \%$ são da raça Persa, e dos entrevistados $4 \%$ não souberam informar a raça de seus animais.

A forma de aquisição dos animais está apresentada no Gráfico 10.

Gráfico 10. Forma de aquisição dos animais.

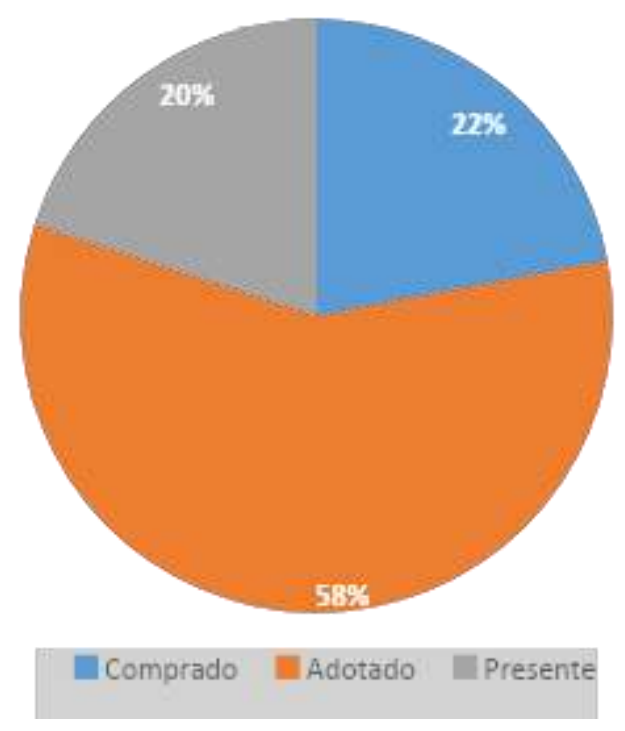

Fonte: Autores (2019).

A respeito da forma de aquisição dos animais, de acordo com o Gráfico 10, podemos observar que 58\% dos animais foram adotados, $22 \%$ foram comprados e $20 \%$ presentes. Diante de tais resultados, convém refletir sobre um levantamento realizado pelo Instituto Pet Brasil (2019), que diz que o Brasil possui 3,9 milhões de animais em condição de vulnerabilidade. Entende-se aqui como animais em condição de vulnerabilidade aqueles que estão sob tutela de famílias classificadas abaixo da linha de pobreza, ou que vivem em ruas, mas recebem cuidados de pessoas. Os animais abandonados não se incluem nessa categoria, que são os que vivem por algum tempo sem um tutor definido. Muitos desses animais abandonados são resgatados por ONGs, que assumem sua guarda até que sejam adotados. O Instituto Pet Brasil verificou a presença de 370 ONGs de proteção animal espalhadas pelo País, que estão na tutela de mais de 172 mil animais, dos quais $96 \%$ são cães e 4\% são gatos.

O sofrimento gerado em animais abandonados é tanto de ordem física quanto emocional, gerando uma grande variedade de emoções, como tristeza, medo, ansiedade e estresse, além de estarem expostos a todos os tipos de adversidades, inclusive maus-tratos. (Gomes, 2013)

Com esse índice tão alto de abandono nas cidades faz-se necessária a conscientização dos tutores a respeito dos benefícios da adoção tanto para o futuro tutor quanto para o animal, como resultado do efeito dessa conscientização podemos observar o aumento do número de animais adotados, tendência observada nos resultados dessa pesquisa, onde mais da metade dos animais citados foram obtidos através da adoção.

Cabe aqui ressaltar também a importância da posse responsável, pois ao passo que uma família decide ter um animal, seja ele adotado ou comprado, assume a total responsabilidade sobre ele, garantindo o suprimento de todas as suas necessidades básicas, além de muito amor.

Em pesquisa realizada pelo SPC Brasil e pela CNDL (2017), a maior parte dos entrevistados que tem um animal de estimação transparece uma conexão natural com seu pet, além de inúmeros sentimentos positivos associados à decisão de compartilhar a vida com o mesmo, observando-se que $62,4 \%$ possuem um animal de estimação por que sempre gostaram de animais, $47,5 \%$ dizem que os animais os fazem se sentir bem e 24,6\% queriam ter companhia. 
$\mathrm{Na}$ presente pesquisa, quando indagados a respeito do que os motivou a ter um animal de estimação, $66 \%$ dos entrevistados afirmaram que sempre gostaram de animais, $18 \%$ afirmaram que os animais os fazem sentir bem, dados semelhantes à pesquisa realizada pelo SPC Brasil (2017), citada anteriormente. Dos entrevistados, $8 \%$ afirmaram terem adquirido um animal de estimação influenciados pelos filhos, que queriam muito um bichinho. Oliveira (2006), afirma que muitas vezes as crianças são fundamentais no momento de aquisição de um animal para a família, pois o convívio das crianças com um animal é "um bom elemento socializador", uma vez que gera na criança um senso de responsabilidade e desenvolve o afeto, diminui a ansiedade e acaba gerando momentos de interação quando o casal tem apenas um filho. Em uma matéria publicada pelo G1- Rio Preto e Araçatuba (2017), a psicóloga Maria Lúcia Madureira comenta que crianças que convivem com animais de estimação expressam afetividade mais facilmente e aprendem sobre regras de convívio, afirma ainda que "As crianças desenvolvem mais rápido as noções de companheirismo e responsabilidade com aqueles que dela dependem. Com o bichinho, elas aprendem a respeitar os horários de alimentação, passeios, necessidades fisiológicas".

Ainda a respeito dos motivos para ter um animal de estimação, $4 \%$ dos entrevistados afirmou que resolveu ter um animal de estimação porque queria ter companhia. Um dos entrevistados (2\%) relatou que tinha pânico e uma psicoterapeuta o incentivou a enfrentar o medo sendo tutor de um animal de estimação e outro entrevistado (2\%) relatou que o que o motiva a ter animais de estimação é o amor à vida.

Em seguida, os entrevistados foram indagados a respeito dos pontos negativos em ter um animal de estimação, onde 46\% das respostas revelaram que os entrevistados acreditam não haver pontos negativos em ter um animal de estimação. A segunda resposta mais comum foi não ter com quem deixar o animal se precisar viajar, representando $40 \%$ das respostas, $16 \%$ relata que ter que limpar a bagunça é um ponto negativo e apenas 14\% consideraram gastos com veterinário/pet shop um ponto negativo em ter um animal de estimação. Na pesquisa realizada pelo SPC Brasil e pela CNDL (2017), 52,6\% dos entrevistados relataram que o ponto negativo é a dificuldade para viajar por não ter com quem deixar o animal, 46,7\% indicou ter que limpar a bagunça/sujeita, 35,5\% custos com o veterinário e 24,4\% custos com Pet shop, 10,9\% dos entrevistados afirmaram não haver nenhum ponto negativo em ter um animal de estimação, sendo oposto ao dado encontrado na presente pesquisa, onde a maioria afirmou não haver pontos negativos.

A visão dos tutores a respeito dos itens essenciais a serem proporcionados aos seus animais está apresentada no Gráfico 11.

Gráfico 11. Visão dos tutores a respeito dos itens essenciais a serem proporcionados aos seus animais.

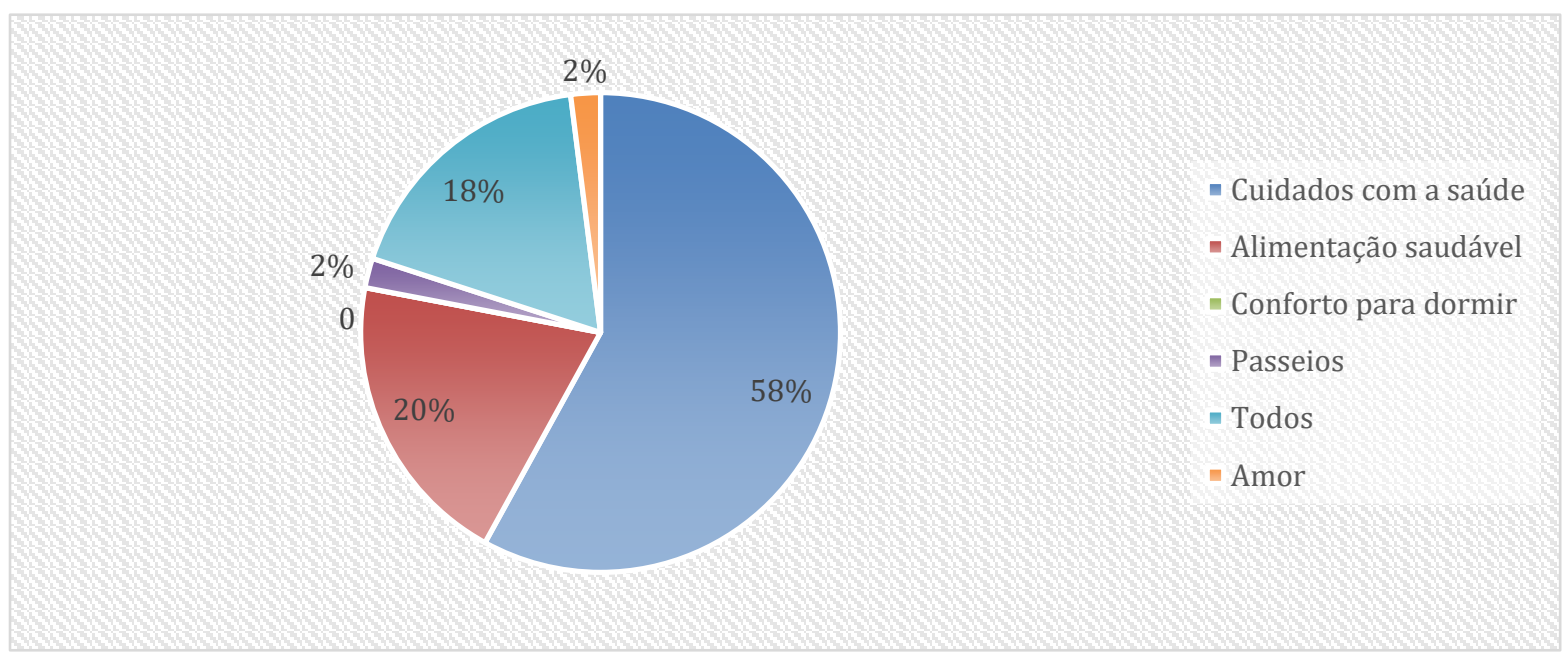

Fonte: Autores (2019). 
Em relação à visão dos tutores a respeito do que consideram essencial para proporcionar aos seus animais, foram expostos a quatro opções: cuidados com a saúde, alimentação saudável, conforto para dormir e passeios. Como se pode observar no Gráfico 11, dos entrevistados, 58\% consideram que o cuidado com a saúde é o item de maior importância a ser proporcionado aos seus animais, o que coincide com as respostas dos ofertantes que afirmaram que os seus serviços mais demandados são as consultas. Dos entrevistados, $20 \%$ considera ser a alimentação saudável, que também coincide com as respostas dos ofertantes que têm como produto mais vendido as rações, $2 \%$ considera os passeios, enquanto que $18 \%$ não conseguiu escolher apenas um item, considerando que todos os itens em conjunto são essenciais ao bem-estar de seus animais. Por fim, $2 \%$ dos entrevistados relataram que o item essencial que deve ser proporcionado aos seus pets é o amor. Em pesquisa realizada pelo SPC Brasil (2017), os entrevistados afirmaram que o item essencial a proporcionar aos seus animais é a alimentação saudável $(79,2 \%)$, seguido de cuidados com a saúde $(78,8 \%)$ e confortos para dormir $(57,6 \%)$. Como citado acima, os entrevistados que não conseguiram eleger apenas um item considerando a soma de todos os itens essencial (18\%) e também a visão dos entrevistados que consideram o amor como item essencial (2\%), ressalta a visão de que os pets são membros da família e precisam ter várias necessidades supridas para que o seu bem-estar seja completo, sendo um sentimento cada vez mais comum entre os donos de pets.

As ações que os tutores costumam realizar para garantir o bem-estar e saúde dos animais estão apresentadas no Gráfico 12.

Gráfico 12. Ações que os tutores costumam realizar para garantir o bem-estar e saúde dos animais.

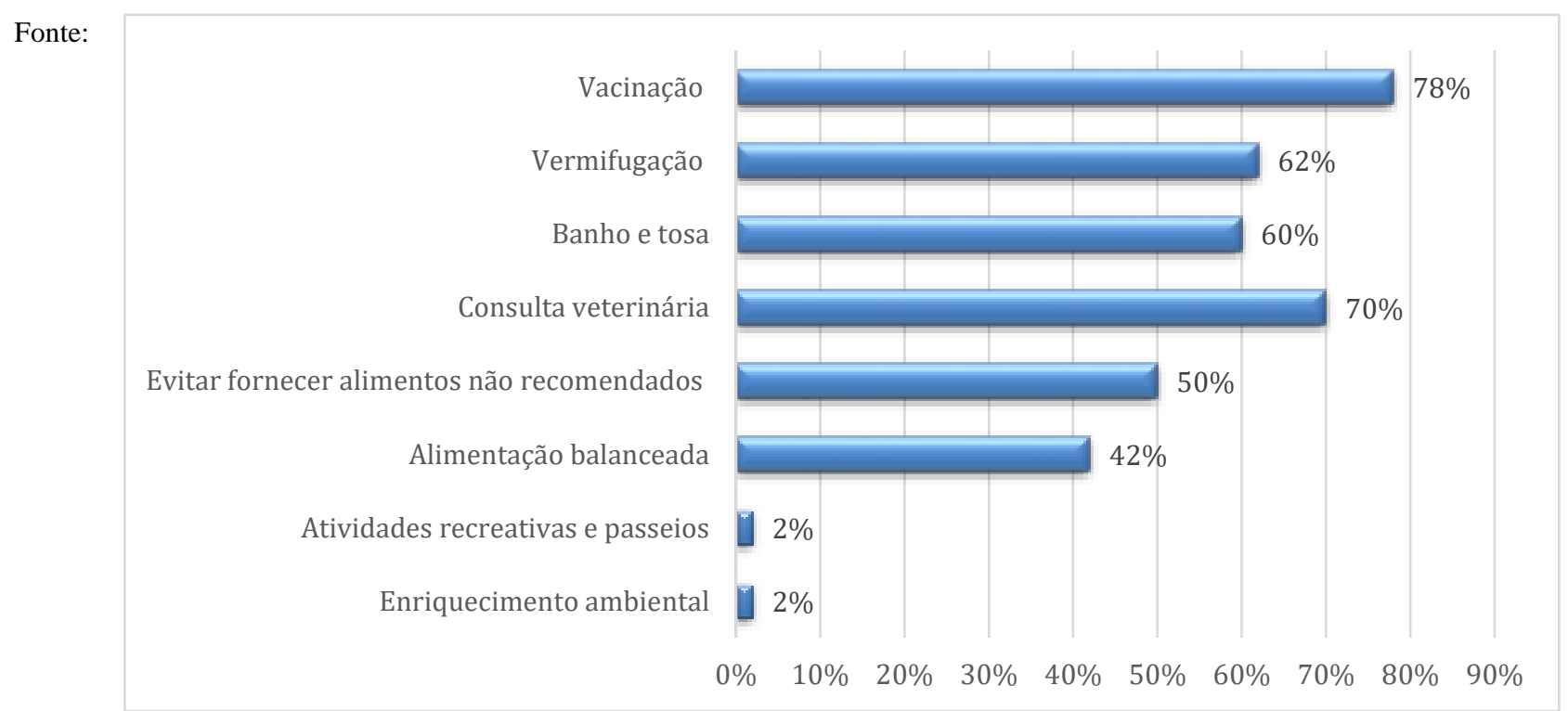

Autores (2019).

No que diz respeito à saúde e bem-estar dos seus animais, os tutores relataram o que costumam fazer. De acordo com o Gráfico 12 , podemos observar que $78 \%$ dos tutores afirmam manter as vacinas atualizadas, $70 \%$ afirmam levar os seus animais ao veterinário para realização de consultas, $62 \%$ afirmam manter a vermifugação atualizada, $60 \%$ afirmam realizar banho e tosa, $25 \%$ afirmam evitar fornecer alimentos não recomendados para animais e $21 \%$ afirmam fornecer alimentação balanceada, $2 \%$ afirmaram sempre fazer atividades recreativas e passeios e $2 \%$ afirmaram realizar enriquecimento ambiental para melhorar o bem-estar dos seus animais.

Os produtos e serviços adquiridos pelos tutores entrevistados estão apresentados no Gráfico 13. 
Gráfico 13. Produtos e serviços adquiridos pelos tutores entrevistados.

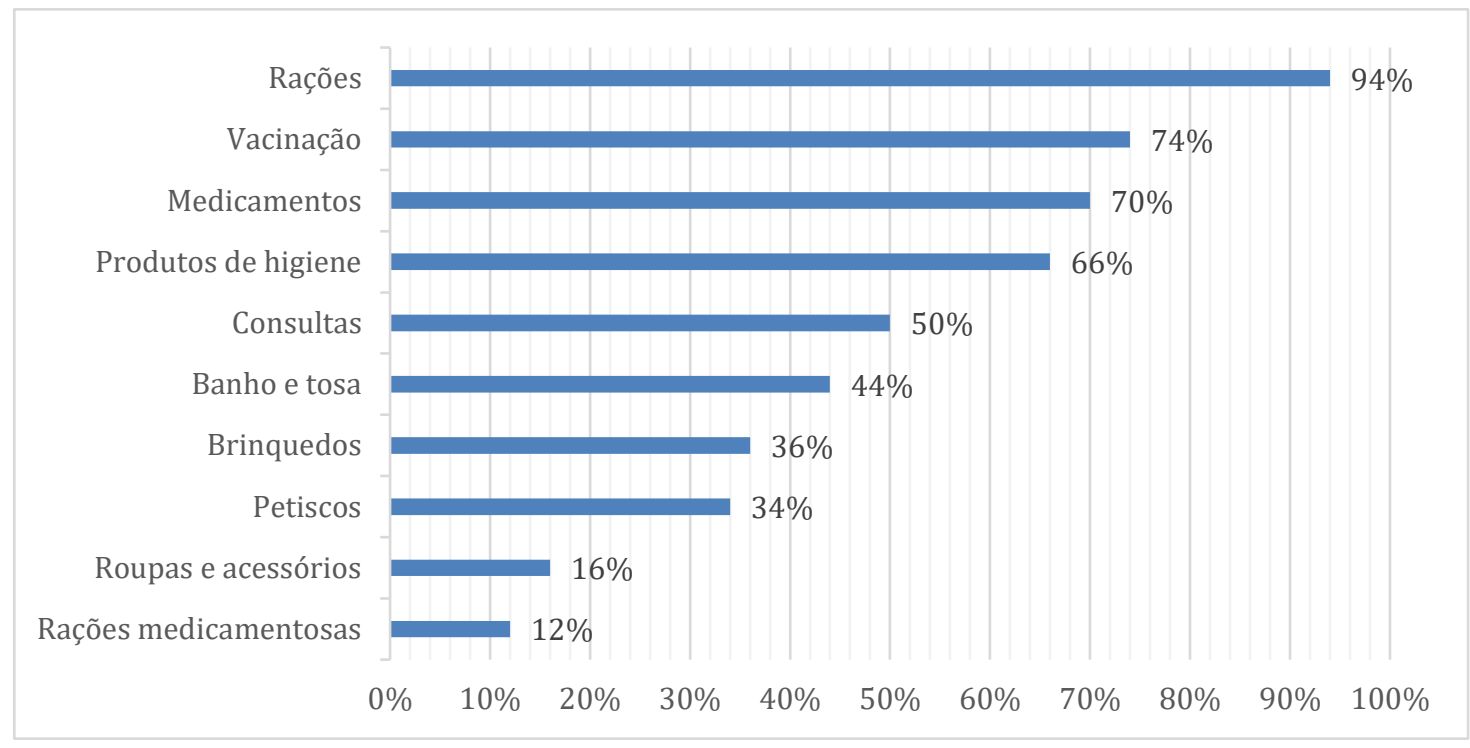

Fonte: Autores (2019).

Os produtos e serviços mais adquiridos pelos tutores entrevistados (Gráfico 13) são em primeiro lugar ração, sendo adquirida por $94 \%$ dos entrevistados, seguido de vacinação (74\%), medicamentos (70\%), produtos de higiene (66\%), consultas (50\%), banho e tosa (44\%), brinquedos para pets (36\%), petiscos (34\%), roupas e acessórios para animais (16\%) e rações medicamentosas (12\%). A ração foi apontada como item mais adquirido, o que faz jus aos dados divulgados pela ABINPET (2018), onde o segmento de pet food foi responsável por 68,6\% do faturamento total do setor em 2017 . O segmento de pet serv foi responsável por $15,8 \%$ do faturamento, seguido pelo segmento de pet care $(7,9 \%)$ e pet vet $(7,7 \%)$.

O perfil dos tutores quanto a procura por assistência médico veterinária está apresentado no Gráfico 14.

Gráfico 14. Perfil dos tutores quanto a procura por assistência médico veterinária.

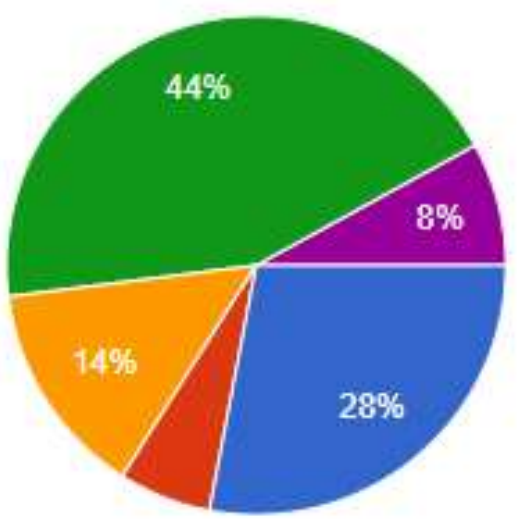

1 vez ao ano

2 vezes ao ano

3 ou mais vezes ao ano

Apenas quando está doente

- Não levol nunca levei ao Médico Veterinário

Fonte: Autores (2019).

De acordo com o Gráfico 14, dos entrevistados, 44\% relataram levar seus animais ao veterinário apenas quando estão doentes, dando a entender que a maioria dos tutores não conhece/não entende os benefícios da medicina preventiva, levando seus animais ao veterinário muitas vezes quando o quadro já é irreversível. Aqui cabe ressaltar a importância da conscientização desses tutores e reeducação a respeito dos cuidados que os pets necessitam. Dos entrevistados, $28 \%$ relataram levar uma vez ao 
ano, $14 \%$ levam seus animais três vezes ou mais ao ano, $6 \%$ levam duas vezes ao ano e $8 \%$ dos entrevistados relataram não levar ou nunca terem levado seus animais ao veterinário.

Os entrevistados foram questionados se em algum momento precisaram se deslocar para outra cidade em busca de algum serviço veterinário, $68 \%$ responderam que não, e 32\% responderam que sim. Dos dezesseis entrevistados que precisaram se deslocar para outra cidade, cinco citaram Areia-PB como cidade procurada, quatro citaram Campina Grande-PB, três citaram João Pessoa-PB e um citou Bananeiras-PB, os três restantes não citaram a cidade de destino. A presença do Hospital Veterinário da Universidade Federal da Paraíba na cidade de Areia-PB pode justificar a ida da maioria dos tutores que afirmaram se deslocar para lá, por ser prestado atendimento gratuito e presença de serviços de diagnóstico como ultrassonografia e radiologia. As outras duas cidades mais citadas (João Pessoa e Campina Grande) são cidades de maior porte, que apresentam maior variedade de serviços.

O gasto médio dos tutores com produtos e/ou serviços veterinários está apresentado no Gráfico 15.

Gráfico 15. Gasto médio dos tutores com produtos/serviços veterinários.
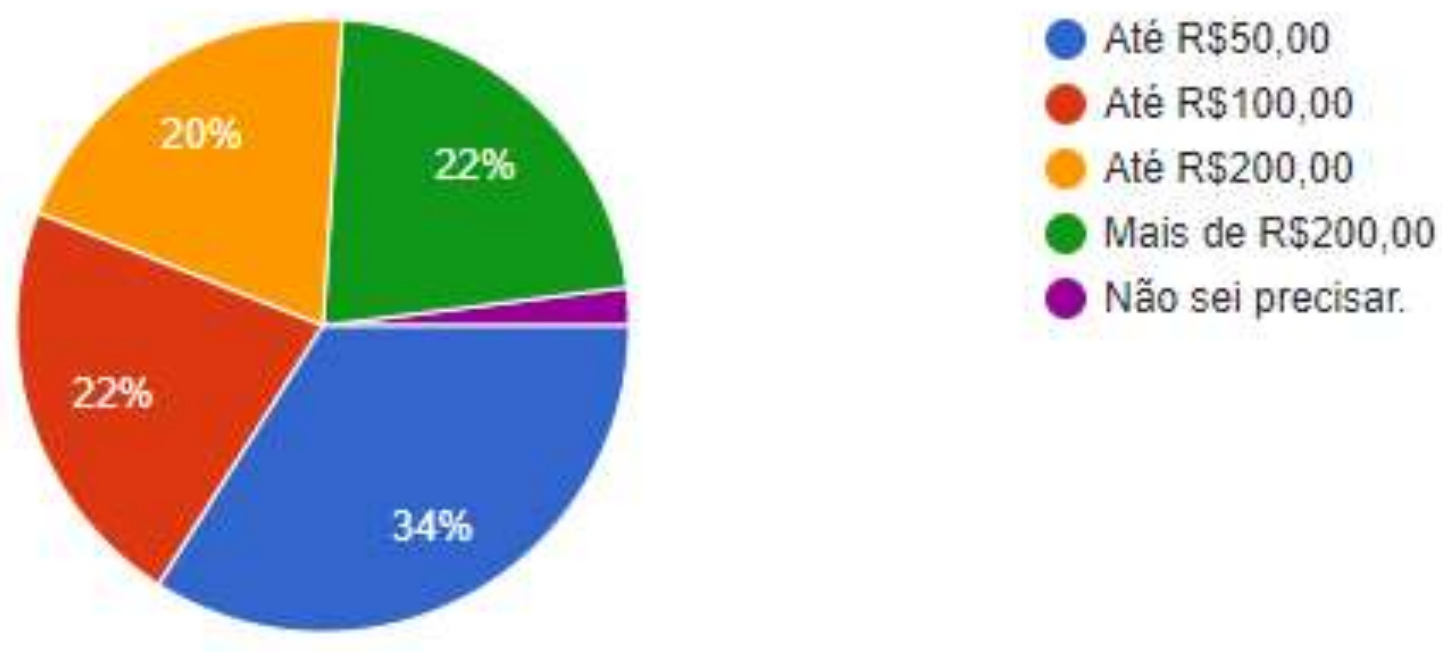

Fonte: Autores (2019).

A pesquisa indica que $24 \%$ dos tutores gastam em média até $\mathrm{R} \$ 50,00$ por mês com seus animais, 22\% gastam até $\mathrm{R} \$ 100,00$, outros $22 \%$ gastam mais de $\mathrm{R} \$ 200,00,20 \%$ costuma gastar até $\mathrm{R} \$ 200,00$ e $2 \%$ não soube precisar o valor gasto mensalmente (Gráfico 15). Nessa questão foram consideradas consultas, banho e tosa, rações, medicamentos e acessórios. A pesquisa realizada por SPC Brasil e pela CNDL (2017) indica que a média do gasto mensal dos entrevistados foi de R $\$ 189,17$, aumentando para R $\$ 223,81$ à classe A/B, 17\% dos entrevistados não sabia ou lembrava o valor gasto.

Além dos serviços veterinários já existentes na cidade de Solânea-PB, 82\% dos entrevistados afirmaram que gostariam que a cidade tivesse serviços de diagnóstico como radiologia, ultrassonografia e laboratório de análises clínicas. O desejo da presença de atendimento especializado, como dermatologista veterinário, oftalmologista veterinário, cardiologista veterinário, entre outras especialidades foi citada por $62 \%$ dos entrevistados. Dos respondentes, $46 \%$ relataram que gostariam que na cidade houvesse atendimento veterinário domiciliar, 36\% apontaram a necessidade de um hotel para cães e gatos, $8 \%$ relataram a necessidade de maior variedade de serviços de banho e tosa e 6\% gostariam que houvesse mais pet shops. Um dos entrevistados (2\%) citou a necessidade de na cidade haver um hospital veterinário completo, além de melhores auxílios da prefeitura com os animais de rua. 
A porcentagem da renda total que os tutores estariam dispostos a pagar por serviços veterinários está apresentada no Gráfico 16.

Gráfico 16. Porcentagem da renda total que tutores estariam dispostos a pagar por serviços veterinários.

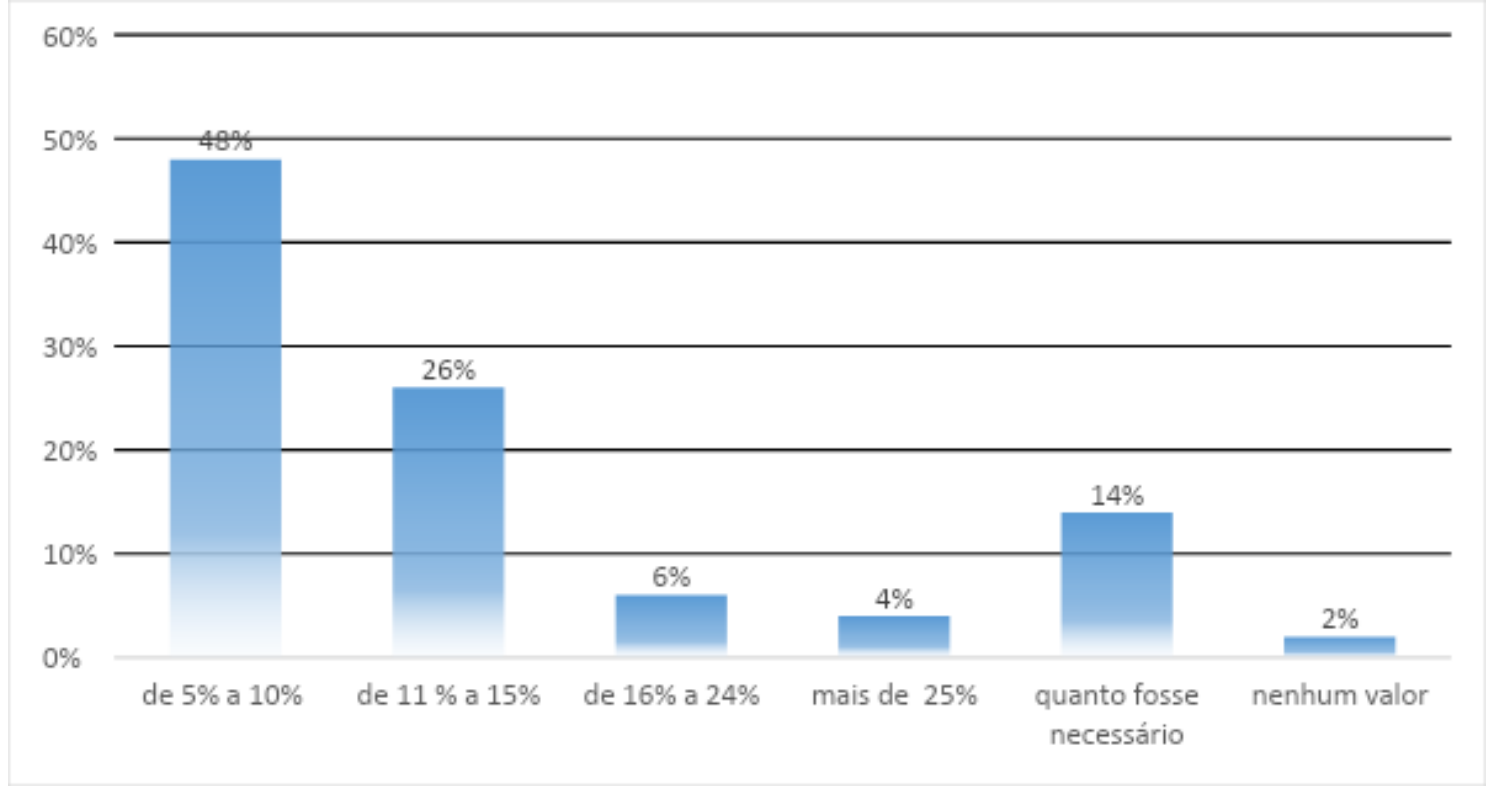

Fonte: Autores (2019).

Foram também questionados a respeito de quanto estariam dispostos a pagar por serviços veterinários, como podemos observar no Gráfico 16, 48\% estariam dispostos a pagar de 5\% a 10\% da sua renda total, 26\% estariam dispostos a pagar $11 \%$ a $15 \%$ da sua renda total, $14 \%$ estariam dispostos a pagar o quanto fosse necessário, $6 \%$ pagaria de $16 \%$ a $24 \%$, 4\% pagaria mais de $25 \%$ da sua renda total e $2 \%$ não estariam dispostos a pagar nenhum valor por serviços veterinários.

As considerações dos tutores ao escolher um serviço veterinário estão apresentadas no Gráfico 17. 
Gráfico 17. Considerações dos tutores ao escolher um serviço veterinário.

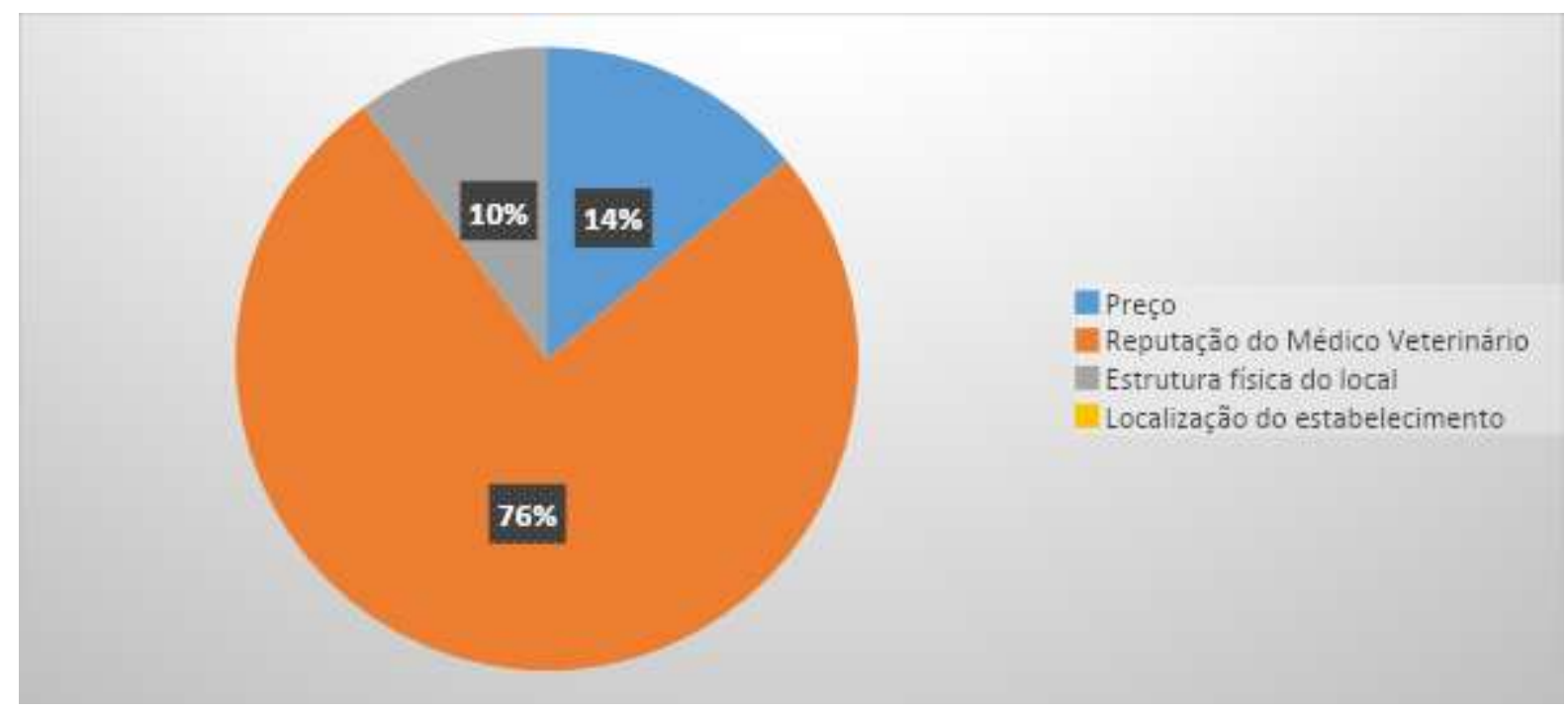

Fonte: Autores (2019).

No momento de escolher um serviço veterinário, os tutores entrevistados consideram que a reputação do médico veterinário é o ponto mais importante, representando $76 \%$ dos entrevistados. Em segundo lugar está o preço, sendo a opinião de $14 \%$ dos entrevistados, $10 \%$ considera a estrutura física do local como ponto mais importante. Nenhum dos entrevistados citou a localização do estabelecimento como critério no momento da escolha (Gráfico 17). Pode-se perceber aqui, que para a maioria dos tutores, a forma como seus pets serão tratados e a relação com a percepção da qualidade dos profissionais tem mais relevância do que outras questões como preço ou estrutura do local, o que diverge da visão dos ofertantes, que relatam que na maioria das vezes os tutores não têm condições de pagar pelos serviços ou não querem pagar o valor cobrado.

Por fim, os entrevistados foram indagados a respeito das maiores falhas que observam nas empresas do ramo veterinário da cidade, onde $66 \%$ afirmaram haver pouca variedade de serviços/produtos ofertados, $26 \%$ relataram que o ambiente é pouco agradável, $22 \%$ relataram que há má qualidade no atendimento ao cliente, outros $22 \%$ relataram longo tempo para ser atendido, $6 \%$ nunca utilizaram os serviços, $4 \%$ não acham que há nenhuma falha, $2 \%$ afirmam que os preços cobrados são muito altos e outros $2 \%$ afirmam que a maior falha é a irresponsabilidade de alguns profissionais.

\section{Conclusão}

Com relação ao perfil socioeconômico dos consumidores do mercado da cidade de Solânea-PB, de acordo com os dados observados, pode-se concluir que a maior concentração de tutores são mulheres com faixa etária entre 18 a 24 anos e acima de 46 anos. Notou-se também que em sua maioria os tutores moram acompanhados, e apenas $6 \%$ moram sozinhos. A maioria dos entrevistados se concentra nas classes socioeconômicas D e E, sendo reflexo das características de rendimento do município, entretanto, mais da metade dos entrevistados afirmou possuir ensino superior.

Em sua maioria, os tutores da cidade possuem cães, seguido dos gatos e em menor quantidade pássaros, jabutis e coelhos. Com relação às raças dos cães e gatos, houve grande variedade citada, e a respeito da forma de obtenção dos animais, mais da metade foram adotados, indicando uma crescente conscientização dos benefícios da adoção tanto para o tutor quanto para o animal adotado.

Sobre as potencialidades do mercado na cidade, conclui-se a demanda por serviços como diagnóstico por imagem, laboratório de análises clínicas, atendimento especializado, atendimento veterinário domiciliar e hotel para cães e gatos, sendo indicado aqui realização de pesquisa mais aprofundada para verificar a viabilidade econômico-financeira de sua implantação. 
Das falhas nas empresas do ramo veterinário do município, sob a ótica dos consumidores, destaca-se a pouca variedade de serviços/produtos ofertados, gerando um desequilíbrio na oferta e demanda, e é considerada uma brecha no mercado para que novos empreendedores possam se inserir. Outra falha citada é o ambiente pouco agradável, aqui podendo-se concluir a grande importância de uma arquitetura e atendimento humanizados para que o cliente seja atendido da melhor forma e seja fidelizado pela empresa.

Sobre a visão dos ofertantes a respeito da sua valorização pelos tutores, metade afirmou que a maioria não tem condições de pagar pelos serviços e a outra metade não quer pagar o valor cobrado. Conclui-se aqui a necessidade do incentivo à educação dos tutores e também dos profissionais a respeito da discussão de preço versus valor, onde é de grande importância que seja discutido com os clientes o valor dos serviços tanto quanto o preço.

A presente pesquisa acadêmica, ao fornecer uma análise mercadológica sobre o setor PET do município de SolâneaPB, por conseguinte, acabou por se inserir na discussão acerca do papel do Médico Veterinário empreendedor, como aquele que estuda o mercado no qual pretende atuar ou já atua, construindo referências para adoção de um planejamento estratégico, perpassando as habilidades técnicas desse profissional.

Sendo assim, tal estudo também pode ser relevante para a reflexão dos recém-formados em relação às configurações do mercado PET, suas tendências, potencialidades e dificuldades, podendo ser replicado (e mais aprofundado) a outros contextos e ambientes de pesquisa, inclusive com amostras mais representativas. Portanto, pode-se sugerir também como trabalho futuro a realização de pesquisa de demanda presente nas cidades para posterior implantação de Pet Shops, Hotéis para pets, Clínicas veterinárias, entre outros. Além disso, pode-se utilizar futuras pesquisas como meio de identificar possíveis pontos de melhoria para estabelecimentos veterinários já presentes no mercado.

\section{Referências}

Aaker, D., Kumar, V. \& Day, G. (1995) Marketing research. John Wiley \& Sons.

Associação Brasileira da Indústria de Produtos para Animais de Estimação. (2018). Mercado Pet Brasil. 2018. http://abinpet.org.br/mercado/

Alcoforado, T. K. F. (2018). Avaliação da viabilidade econômica para implantação de clínica veterinária na microrregião do litoral norte da Paraíba sob a perspectiva do médico veterinário. Trabalho de Conclusão de Curso, Universidade Federal da Paraíba, Areia, PB, Brasil.

Antônio, P., Dutra, K. E. (2008, junho). Pesquisa De Mercado: Ferramenta norteadora no processo decisório que antecede a tomada de decisão. Revista Eletrônica da Faculdade Metodista Granbery, 1, 1-16.

Elizeire, M. B. (2013). Expansão do Mercado Pet e a Importância do Marketing na Medicina Veterinária. Trabalho de Conclusão de Curso, Universidade Federal do Rio Grande do Sul, Porto Alegre, RS, Brasil.

G1 Rio Preto e Araçatuba (2017). Relação entre animais de estimação e crianças traz série de benefícios. G1- Sorocaba e Jundiaí. https://g1.globo.com/saopaulo/sorocaba-jundiai/mundo-pet/noticia/relacao-entre-animais-de-estimacao-e-criancas-traz-serie-de-beneficios.ghtml

Graf, C. T. (2016). O Comportamento do Consumidor no Mercado Pet e a relação entre os Cães e as Pessoas. Trabalho de Conclusão de Curso, UnijuíUniversidade Regional do Noroeste do Estado do Rio Grande do Sul, Santa Rosa, Brasil.

Gerhardt, T. E, Silveira, D. T. (2009). Métodos de Pesquisa. Porto Alegre: Editora da UFRGS. http://www.ufrgs.br/cursopgdr/downloadsserie/derad005.pdf

Gomes, C. C. M. (2013). Guarda responsável de animais de companhia: Um estudo sobre a responsabilidade civil dos proprietários e a entrega de cães e gatos na Diretoria de Vigilância Ambiental do Distrito Federal. Monografia, Universidade de Brasília/Faculdade de Agronomia e Medicina Veterinária, Brasília, Brasil.

Instituto Brasileiro de Geografia e Estatística (2015). Pesquisa Nacional de Saúde 2013. Acesso e utilização dos serviços de saúde, acidentes e violências: Brasil, grandes regiões e unidades da federação. Rio de Janeiro: IBGE. https://biblioteca.ibge.gov.br/visualizacao/livros/liv94074.pdf

Instituto Brasileiro de Geografia e Estatística (2017). Panorama Solânea-PB: Salário médio mensal dos trabalhadores formais. https://cidades.ibge.gov.br/brasil/pb/solanea/panorama

Instituto Pet Brasil. (2019). País tem 3,9 milhões de animais em condição de vulnerabilidade. http://institutopetbrasil.com/imprensa/pais-tem-39-milhoes-deanimais-em-condicao-de-vulnerabilidade/

Mattar, F. (1996). Pesquisa de marketing. Ed. Atlas. 
Research, Society and Development, v. 10, n. 9, e4710917647, 2021

(CC BY 4.0) | ISSN 2525-3409 | DOI: http://dx.doi.org/10.33448/rsd-v10i9.17647

Mercader, P. (2013). Preços: os dez erros mais comuns dos veterinários. In M. A. GIOSO. Gestão da clínica veterinária: como gerenciar finanças, equipes e marketing a seu favor (Cap. 10, p. 62). Elsevier.

Muller, D. V. (2012). Estudo de Viabilidade Econômica do Segmento de Pet Shop no Município de Ijuí. Trabalho de Conclusão de Curso, Universidade Regional do Noroeste do Estado do Rio Grande do Sul, Ijuí, Brasil.

Oliveira, S. B. C. de. (2006). Sobre Homens e Cães: Um estudo antropológico sobre afetividade, consumo e distinção. Dissertação de Mestrado, Instituto de Sociologia e Ciências Sociais, Universidade Federal do Rio de Janeiro.

Pereira, A. S. et al. (2018). Metodologia da Pesquisa Científica. UFSM. https://repositorio.ufsm.br/bitstream/handle/1/15824/Lic_Computacao_MetodologiaPesquisa-Cientifica.pdf?sequence $=1$.

Poli, M. (2017). Mercado pet cresce graças a mudanças no comportamento dos donos de animais de estimação. Você S/A. https://vocesa.abril.com.br/geral/mercado-pet-cresce-gracas-a-mudancas-no-comportamento-dos-donos-de-animais-de-estimacao/

Santos, T. S. dos, Schmitt, C. I., Ochôa, T. L., Mendonça, F. R. (2021, maio). Presença de pets e sua relação com seus tutores. Research, Society and Development, 10,6 .

Scaramuzzo, M., Scheller, F. (2019, março). Classe C volta a crescer, vê futuro com otimismo e deixa consumo-ostentação. O Estado de S.Paulo. https://economia.estadao.com.br/noticias/geral,classe-c-volta-a-crescer-ve-futuro-com-otimismo-e-deixa-consumo-ostentacao,70002757934

Serviço de Proteção ao Crédito Brasil, Confederação Nacional de Dirigentes e Lojistas. (2017). Mercado de Consumo Pet 2017. https://www.spcbrasil.org.br/pesquisas/pesquisa/3540

Stoeckel, L. E. et al. (2014). Patterns of Brain Activation when Mothers View Their Own Child and Dog: An fMRI Study. PLOS ONE. https://journals.plos.org/plosone/article?id=10.1371/journal.pone.0107205\#references. 10.1371/journal.pone.0107205 